\title{
Why is Governance Invalid at the Grass Roots of Society?
}

\author{
Jing Zhang ${ }^{1}$
}

Received: 11 March 2016/Accepted: 11 March 2016/Published online: 11 April 2016

(C) Fudan University and Springer Science+Business Media Singapore 2016

\begin{abstract}
This article aims to explore the reasons for the plight of Chinese grassroots community governance produced. The article points out that the organizational structure of Chinese society has undergone major changes: it is the transition from the "danwei" society to the public society. On the one hand, the substantial reduction in the "danwei" population covered and on the other hand, responsibility of "danwei" for its members is also greatly reduced. This leads to a lot of grassroots people not only lost could be relied upon organization which take responsibility to help them solve the problem, but also lost their rights to facilitate the achievement of the channel system, So "social justice" supply has shrunk dramatically.
\end{abstract}

Keywords Governance $\cdot$ Social structure $\cdot$ Change $\cdot$ Organize channels $\cdot$ Social justice

\section{Introduction}

The Chinese society has witnessed unprecedented changes in history over the past three decades. The huge achievements in the economic growth gradually sets off the lagging issues of the society-this is reflected by the increasing social conflicts, prominent differences in the value outlook, general perception of increasingly larger work pressure among the grassroots cadres, "unmanageable" masses and cadres lacking "popular trust". ${ }^{1}$ These factors have intensified the politicization of social

\footnotetext{
1 An Interview with Grassroots Cadres of Lishui, Zhejiang Province, August 2015.

Jing Zhang

pkuzhangj@126.com; soczhangj@pku.edu.cn

1 Department of Sociology, Peking University, Beijing 100871, China
} 
sentiments: individual events tend to upgrade to group events and legal issues have a tendency to be converted into accountability ones against public organizations. It has become a challenging problem for the field of governance studies why the once solid and deep-going social governance system at the social grassroots level gets into trouble.

Scholars differ in their opinion about the explanation of this issue. A mainstream viewpoint concludes that the enlarged differences on income and status as well as the solidified social mobility have intensified the social grievance (Li and Sun 2009; Mao 2013; Wu 2012; Li et al. 2011; Sun 2011); another viewpoint maintains that China lacks a democratic system (Zhang and Bai 2014), so that the masses change their thinking and have become increasingly resistant to governance along with the competition of external ideologies (Yao 2005), The third viewpoint suggests on the basis of historical studies that governance failure is the outcome of the downward integration ability of the state; the fourth viewpoint argues that the economic behaviors of cadres lead them to competition for benefits with the masses, which not only infringes on people's immediate interests but also prejudices the moral standing of cadres, whereby the governance authority fails naturally (Lin 2014).

These disagreements with different perspectives offer an answer either from the aspect of social and economic changes, or in terms of the political system or cadres' behaviors. Despite the enlightening effect, some obfuscation still cannot be settled. For example, why is the grievance not necessarily from the group with the lowest income and social status in China?. ${ }^{2}$ Why do people generally acknowledge that the income gap is justified on a reasonable basis and that the level of income should be varying with occupation? For more than half a century, the Chinese political system has not witnessed any significant change, but why has there been a sharp increase in petitions during recent years and serious failure in social governance? Despite the fact that the mainstream media has not abated its ideological publicity, why is the "contest" efficacy weakened after all? Why is the national ability of integration on the decline? In a place with more "bad cadres", the discontent of local masses is high or logical, but why could the "good cadres" with different behaviors hardly reverse the predicament of the overall social governance as the grassroots governance is generally declining? Such confusions indicate that some empirical and theoretical issues about the failure of social governance are yet to be revealed in a profound way.

\subsection{Problems in the Study of Social Governance in China}

Empirically, part of the explanations only focuses on the differential change in the economic status and presumes that social members constitute the immediate

\footnotetext{
${ }^{2}$ Liu Ran, Peng Ge, A Survey Report of the Sense of Happiness of Urban and Rural Residents in Beijing, Baidu Library, Professional Materials, Sociology; http://wenku.baidu.com/view/ 82e48b28e2bd960590c6770b.html. The Research Group of Chinese Livelihood Index of the Financial and Economic Affairs Committee, National People's Congress, A Survey on the Sense of Happiness of Urban Residents in China in 2010, Baidu Library, professional material; http://wenku.baidu.com/view/ e10f311fa76e58fafab003fd.html.
} 
interests of the economic status, but they lack attention to the institutional means to realize their rights. In fact, the possession and adoption of this approach in a convenient way are also dependent on people's immediate interests. Even though the social status and income are different, there is always an opportunity to rectify or compensate for unfair deviation only if the institutional approach of problem solving available to people is effective. However, if such approach is only available to certain people, what kind of people more likely join the contest and accountability and challenge the governance order?

For example, towns in China have generally established the housing fund system in which laborers, employers and the state are required to establish the fund reserve account according to proportions, with a view to providing low-interest loans for laborers who intend to buy houses. However, in practice, many people cannot gain benefits from such system. Although the law clearly prescribes such equity of urban workers, not everyone can realize account saving, let alone the use. The kind of labor force which tends to flow frequently in the labor market and has to change the nature and place of occupations as they have no long-term work unit, and those who work outside the institutional units, cannot maintain this account since there are no formal service channels: there is no specific organization (generally work units) which is responsible for recording, saving, transferring and handling such business. Such laborers cannot enhance their ability of buying houses with the aid of the housing fund system, which, as a result, damages their "immediate interests" naturally. This example reveals apparently that the damage to people's interest is not attributed to the difference in income and status, but that in the "regular channels" to realize their own rights and interests. Such difference leads to injustice which cannot be improved by individual efforts or market purchase or by virtue of interpersonal relationship.

It is common nowadays that the difference in social economic status exists in all societies. However, it stands to reason that not all societies are discontented with the public organizations. Why is there such a difference? Why are some social differences non-political while others are transformed into political protests? These issues cast light on the following problems: the relationship between socioeconomic status and political discontent may not be so straightforward, and the exploration needs to cover some more fundamental influencing factors, which perhaps play a key role in the course of either converting social differences into political discontent and to constitute a difficulty in governance, or alternatively removing the political dissatisfaction among the social differences to find out a way out of the difficulty in governance.

The absence of historical facts is another reflection of the insufficient persuasive power of part of above-mentioned explanation. For instance, if the absence of a democratic system is an important reason of governance predicaments, China which is always in lack of a democratic system should, to a logic extent, stand among the grassroots governance crisis. In other words, China also had no democratic system in the first three decades, but why did not China face a predicament of social governance as it does today at that time? In the Chinese society, the political systems in various places do not present the major differences, but why do people live and work peacefully in some places but induce the frequent outbreak of 
noncompliance and protest in some others? To make the answers more persuasive, we need to ponder over them in concrete, instead of abstract proposition. In methodology, this does not deny the significant role of the democratic system in a general sense, but to keep a questionable attitude towards the answers of specific questions: is China's grassroots governance failure related to the "democratic system" in terms of historical facts?

Third, part of the above explanations need to be explored deeply as they lack certain details. For example, what are the features of "state capacities" under the Chinese mode of social governance? What is the relationship between "declining state ability of integration" and "grassroots governance failure"? Which factor is the reason and which factor is the result eventually? Why is the social integration ability on the decline while there is an increase in the state financial revenue, enhancement in the resource absorption and heightened control over the market? Another example is the interpretation of cadres' behaviors. We need to ask as to why do cadres generally shift the responsibilities and make buck-passing. If the personal conduct or morality of cadres can account for the issues concerning overall governance predicament, why is the limited improvement achieved in social governance while the state has intensified the investigation for the cadre's behaviors in recent years?

To dispose of these confusions, we need to explore a new perspective and look for a more fundamental relationship between factors. The so-called "fundamental factors" should satisfy the following conditions: it shall be systematic (overall situation), but not personal, occasional and expectable (policy targets); it is able to explain more variations and remains in conformity with the historical facts of the explained society. I attempt to search for an answer from the structure of China's grassroots governance and make examination in the historical course. My goal is to unveil the historical origin and features arising from the accountability among relevant governance roles as well as their relationship with a new social environment and objects of governance.

\section{Traditional China}

The traditional governance structure of China can be divided into two different parts: the supertratum was the bureaucratic establishment system controlled by the imperial power, while the grassroots are the local control system controlled by the head of a clan or a country gentleman. Such governance was basically characterized by the combination of two cases: the unified symbolic system of cultures and ideology consolidated by an imperial examination system and the practical partition system of the grassroots society in which a number of power centers distributed at the grassroots implemented the social governance. Among them, country gentlemen of villages at all places assumed the important role of responsibility. They lived in the grassroots ethnic group which they belonged to and owned land properties and public prestige. Commonly known as "local prominent figures", they handled the daily local affairs and undertook the functions of "ethical education" involving legislation, jurisdiction, law enforcement and education. The gentries or clan heads 
had no official capacity, but they put a premium on the communication with officials. They had an intercourse with the government, but this does not mean that they invited to join the governance course, but rather protection was guaranteed to some extent. The imperial power under this mode, as it were, was to govern the local society with the aid of power of local gentry, namely local authorities, instead of replacing them.

Although such partition situation was not recognized by the formal bureaucratic establishment system either in oral or in written forms, the signs for partitioning were actually "ubiquitous" (Fei 1953, 83-84). This means that in traditional China there were actually two "non-interference" governance fields. For the grassroots society, the imperial power only had the symbolic cultural significance while the power of local gentry had the actual significance of administration and governance. The state had not sought for the real and challenging power of administration of the local society only upon the symbolic acknowledgement of locality (Shue 1988); even in terms of the governance details, the state also had not actually promulgated the uniform governance rules, but approved the locality to "make convention-based judgments". In such a case, the transformation of the state "according to the local actuality" on the principle of abstraction made it suitable to local actuality. This was the justified procedure recognized by all parties.

However, such governance mode changed in modern times. The recurring chaos caused by war forced the state to expand recruitment of soldiers and manage to increase the agricultural tax. Correspondingly, the state strengthened the mobilization of grassroots resources and the organizational system, and local social governance also gradually fell within the official governance. In modern times, the state manages to transform the local powers into the branches of government regime at the grassroots level through a series of structural establishment and appointment. The local powers are gradually transformed and play a role in the national objectives-recruitment of soldiers, tax collection and tax return. Such a "bureaucrat" process of local powers (Zhang 1991), involved the basic framework of the original social governance: the foundation of powers of grassroots administers was gradually transferred to the government systems; as a result, its mutual dependence on the local society disintegrated gradually. The disintegration was also intensified along with other changes: the urbanization and industrialization of China in modern times, the cancellation of imperial examinations and the establishment of Westernstyle education. These changes disabled the systems of education (enlightenment) originally established at grassroots level. The offspring of country gentlemen who received the new education gradually left the countryside to settle in cities where they started new business. These factors jointly aggravated the decline of the grassroots governance.

\section{Social Reorganization}

The political reform that took place in the 1950s reorganized China's social governance structure. A great number of administrative organizations, enterprises, agricultural production organizations and collective organizations were established 
in cities and rural areas, which were called "administrative units" by the Chinese. Most of the social members were governed under certain area of jurisdiction either by working or through the administration unit for household registration. In cities, these units mainly served as administrative utilities or enterprises while in villages they existed in the forms of people's communes, production brigades and administrative villages. The units not only functioned as the "factories of social organizations" (Walder 1996), to organize production, but also served as social organizations to manage the behaviors of employees or members of the society, handle disputes and provide social benefits. The units were also political institutions whose levels and statuses in the national system may determine the status, power and political promotion of employees, influence the survival resources available to them-the amount of promotion, opportunity and various benefits. As a result, the people organized by the units across the state formed the sequence of hierarchical organizations. In units, people not only gained salaries but also remained relevant to the public institutions and shared the distributed public resources. This means that a special type of organizational relation between individuals and the public came into being: people obtain a position and the corresponding entitlements in the public system after they become members of such units (Zhang 2015a, b). A unit is fully "responsible" for its members and plays an organizational role of liaison, coordination, accountability and representation among the public system and social members, thus laying a foundation for its grassroots governance responsibilities.

Unlike the traditional society, the units constitute a part of the official system, which is equivalent to an institutional channel for common people to approach the governmental organization "indirectly", although they somewhat have flexibility in the development of internal policies. There are cross-class, trans-national and crossfamily organizational relations with clear hierarchy and subcontracting of jurisdiction areas among units. The realization of ordinary personal interests does not consist in laws and regulations, but in the units that they belong to, since the units are the "executing" parties of the institutional set-up. The units with a border and administrative area are only responsible for the registration of members within their domains. Most social issues are solved in the units or submitted to the government for handling. However, the government services are "for organizations instead of individuals". On the crucial intermediary position, the society of units covers a wide range and forms the governance structure of three-level connectivity (state, units and individuals) on the whole. Under the system of responsibility (the person who is in charge of his/her members), each person in the units is organized into the national redistribution system of resources. The government is highly dependent on such "agencies" to master information and handle problems. As the government does not need to handle the social governance by itself, it does not develop its accountability of facing the society. For social governance, the role of units resembles agencies of public organizations at the grassroots level. Hence, the public sectors in the society are seemingly limited, but actually the "agencies" engaging in social governance are everywhere. 


\section{Dual Governance System}

This is actually a dual governance system which consists of two governance rolesgovernments and work units with different functions. The government functions to make decisions, approval and redistribute resources, mainly embodied in making of plans, issuance of directives and allocation of resources. The units function to execute and take charge of governance, mainly embodied in implementing government mandates, allocating resources and providing the public articles within the area of jurisdiction. In this system, the government governs the units, which in turn govern social members. The government does not need to directly face the people in the social governance, but to govern the society via the units"agencies". Therefore, the government is alienated from the masses, so the members of the society neither need nor have the right to contact the government. In other words, the people are not allowed to contact the government by surpassing their responsibilities. Once such circumstance happens, the government deems it as the dereliction of duty of the units and requires the units to take back the personnel and handle the case. Such role is widely recognized by government bodies, which may serve as an explanation of common government buck-passing and interpreted appeal of units.

For social governance, the most noteworthy point is not the "administration" function of units, but other roles of the units: connection-responsible for "organized submission" of the appeals of social members to higher authorities; coordination-responsible for settling the disputes in the units and among units; accountability - responsible for responding and solving the needs of unit members; representative-responsible for striving for policy and competitive equities on behalf of all unit members; protection-responsible for screening the submitted information and internal error correction, so as to reduce the external risks that the unit members are faced with. The key of political functions of these roles: Through accountability, representative, protection and coordination, the units assume the function of error correction at the grassroots of the society. The active existence of such function actually provides the most important public goods: it can enable a majority of common people to experience it. Although it is piecemeal, it is indeed the social supply of justice as needed. These functions of the units are very essential for social governance.

Judging from the society as a whole, what should not be ignored, in particular, is that the above-mentioned functions of units mean the change in organized "units" of social benefits, which impose major impacts on social governance: As a matter of fact, this re-establishes the dependency relationship of individuals on public organizations, and "liberates" individuals relatively from their dependence on such organizations as classes, nationalities and families, etc. This not only establishes the community of unit benefits crossing classes, nationalities and families, but also enables it to connect with the national distribution system of resources. From the perspective of political sociology, this is equal to restructuring an organized group for the benefits of social members, whereby the mobilization capacity of such original organizations as classes, nationalities and families...is weakened; however, 
on the contrary, the new organization interests characterized by "administrative contracting" and the governance of units are strengthened mutually. In this view, the society is governed by a single national organization on the surface, but actually the governance is completed by multiple organizations with discretion. Maybe such governance has an integral form, but the real power of control is still held by the units to a greater extent (Zhang 2014). Therefore, we have seen fewer signs of the effect of classes, nationalities and families in the major social conflict events; however, on the contrary, the interest contention based on the border of units is normal (Zhang 2012).

Before the mid-1990s, the effect of such a "new" dual governance system explains why social governance was retained. The intermediary status of units between individuals and common mechanisms serves as the structural basis for the survival of national "integration ability". Such structure successfully "digested" the motive power of social conflicts into public areas (other than units). Even during the period of political unrest at the national level, the order of grassroots was not disintegrated completely just because the governance functions of units exist roughly.

\section{Changes in the Organizational Structure}

Since the mid-1990s, there have been two social changes which led to significant impacts on the above governance system. One of them lies in the wide-ranging social mobility, both in cities and rural areas where an increasing number of people left the "units". In 1995, the number of employees in the state-owned and collective enterprises still accounted for $59.1 \%$ of the urban employees. In 2008, the number of employees in state-owned and collective enterprises only accounted for $23.5 \%$; however, this figure dropped to $18 \%$ in 2013. Up to 2012, the number of employees in administrative organs, enterprises and institutions accounted for $4.5 \%$ of the total urban employees. ${ }^{3}$ Even if we added up the above two figures together, it only accounted for no more than one-fourth of the urban employees. So the relatively classical governance mechanism of units still prevailed. During the 8 years from 2002 to 2009, among the higher education graduates belonging to the category of arts and science of law, those who entered administrative organs, state-owned (enterprises, institutions) units, military organizations, financial institutions, scientific research departments, higher education institutions and medical units dropped by 325,000 . The basic trend of employment of science graduates was almost similar. ${ }^{4}$ In rural areas, the number of natural villages dropped from 3.63 million to 2.71 million during 10 years from 2000 to 2010 . More than 900,000 natural villages vanished. $^{5}$

\footnotetext{
${ }^{3}$ National Bureau of Statistics of the People's Republic of China: http://www.stats.gov.cn/tjsj/.

${ }^{4}$ According to the Department of College and University Students, the Ministry of Education, 2002-2009. The "category of law" is a general category of official classification of arts, including a majority of specialties of Social Sciences, Humanities and Management Science.

${ }^{5}$ Statistics of Reporters' Interviews, China Youth Daily.
} 
The other change is the diversified development of work organizations, which leads to the emergence of new organizations with more employees under the market environment, but such new type of organizations is very different from the traditional counterparts in the role of governance: they rarely or hardly serve as the "agencies of government" and assume simpler "responsibilities" for employees. These market organizations are characterized by different interests and objectives, and even the parts that remain conflicting but (relatively) independent in status and (relatively) equal in rights carry out cooperation through agreement and exchange. This is different from the organizational structure of original units with the executive hierarchy. The latter carries out "cooperation" among the action bodies that are consistent in interests and objectives (at least non-confrontational), clear in ownership level, dependent status and asymmetrical powers, through indication and execution. The major difference of two organizations rests with the relationship of powers and affiliation among organizations: in aspect of responsibilities and missions, the market organizations are independent and competitive mutually. They are neither a whole nor share the common interests and objectives (Zhang 2014). In these new organizations, fewer employees can enjoy the responsibilities and functions of the past classical unit mechanisms, such as connection, accountability, coordination, representatiion and protection.

What problems in governance will this give rise to? For many people, the only responsible organizations that are approved and irreplaceable disappeared around them. When more and more people change jobs and leave the original organizations, "governance by units" loses the significance for them. This meant that a great number of social members lost their statuses in the public system; as a result, the equities endowed by laws and public regulations can hardly be realized by means of organizations. To this end, the social mechanism balancing the interests around people no longer existed, whereby no solutions are available for many conflicts naturally and the perceived injustice is gradually accumulated in the society. To address such issues, people surpassed the border of units and got in public domain for their needs of "justice". They requested for arbitration through appeals and events, with an eye to initiating the state intervention in solving the problems.

\section{Individual Settlement of Disputes: Different Selection Channels}

If the above judgment is reasonable, the number of people who settle the disputes through the units they belong to will be on the decline logically while, on the contrary, the number of those who make claims via a larger public channel-the government, appeal to higher authorities, legal institutions and media; as they experience injustice and such injustice cannot be addressed effectively, they got involved in collective events for other reasons so that the number of people who help the parties concerned "seek justice" will rise. The change in these aspects is evidenced by more and more survey data (Table 1).

The first three options with a relatively higher percentage are, respectively, about unemployment insurance, land acquisition and restructuring of enterprises. They are the fields where the traditional grassroots units play their roles. Unemployment 
Table 1 Frequency proportions of various disputes

\begin{tabular}{ll}
\hline Type of dispute & $\begin{array}{l}\text { Proportion in the number of } \\
\text { samples with disputes }\end{array}$ \\
\hline Property disputes & 15.79 \\
Land acquisition & 24.83 \\
Urban relocation & 10.98 \\
Restructuring of enterprises & 21.62 \\
Unemployment insurance & 26.60 \\
Distribution of house sites & 11.06 \\
Grassroots election & 11.15 \\
Dispute over obligations & 13.94 \\
Others & 8.11 \\
Total & 144.08 \\
\hline
\end{tabular}

The number of valid samples with disputes over the past 5 years: 1184 (multiple choices)

The statistics are sourced from the data of Renmin University of China CGSS2006 Chinese National Survey Data Archive, made by Dong Yanfeng

insurance and restructuring of enterprises involve urban work units while land acquisition largely involves rural institutions and village committees which manage over collective properties. However, evidently the effect of these units is so disappointing that people make fewer choices somewhat in the "problem-solving" institutions and units. This indicates that the functions of units in terms of connection, coordination, accountability, representation and protection are shrinking (Table 2).

The data of CGSS2006 also showed that the relevance between individual motivation of joining the collective action and individual material benefits is weakened. When a collective action is "irrelevant" to individual benefits, individuals join a collective action just for "reason of value". Such selection is obviously related to the fact about whether "they suffered injustice". That is to say, the individuals who suffered injustice are more likely to join a collective action (Table 3). When the participants in a value-oriented collective action increase, is it

Table 2 Willingness frequency proportions of appealing divisions

\begin{tabular}{lc}
\hline Appealing division & Percentage (\%) \\
\hline Unit leaders & 14.66 \\
Local government & 49.32 \\
Court & 16.02 \\
Social organizations for workers, youth, women, etc. & 2.12 \\
Non-governmental organizations & 3.39 \\
Others & 14.49 \\
Total & 100 \\
\hline
\end{tabular}

The number of valid samples is 1180 
Table 3 Involvement of value-oriented collective actions: regression of the influencing factor logit

\begin{tabular}{lllll}
\hline Variable & Hybrid model & \multicolumn{3}{l}{ Involvement of value-oriented collective action } \\
\cline { 3 - 5 } & & Model 2a & Model 2b & Model 2c \\
\hline Injustice experience & $1.115^{* * *}$ & - & - & $1.140^{* * *}$ \\
& $(0.195)$ & - & - & $(0.371)$ \\
Constant term & $-0.852^{*}$ & $-1.004^{*}$ & -0.215 & -0.252 \\
& $(0.484)$ & $(0.601)$ & $(0.681)$ & $(0.698)$ \\
$N$ & 731 & 493 & 493 & 493
\end{tabular}

Robust standard errors in parentheses

$* * * p<0.01 ; * * p<0.05 ; * p<0.1$

The statistics are sourced from the data of SCSS2006, made by Xin Guang

Table 4 Whom will you turn to for help when you are treated unfairly?

\begin{tabular}{ll}
\hline Appealing division & Percentage $(\%)$ \\
\hline Court & 71.3 \\
The Party and government departments & 59.0 \\
$\quad$ (including the departments for workers, youth and women) & \\
Negotiated settlement among individuals & 36.7 \\
Seek help from media & 24.3 \\
Letters and visits & 15.9 \\
Handling within the unit & 13.8 \\
Total & 221 \\
\hline
\end{tabular}

Valid samples: 800 (multiple choices)

The statistics are sourced from the data of National Social Mentality Survey in 2015, collected by National Bureau of Statistics

related to the waning mechanism of grassroots error correction (providing social equity)?

The above data are sourced from 2006. Recently, the national survey data (2015) from another independent channel shows that people's options of settling disputes and means of solving problems are developing rapidly with the same tendency: The respondents use at least one channel of appealing to the higher authorities, but the probability of selecting units ranks much lower compared with the data of 2006 (Table 4). Does it predict that the efficiency of units in the social governance declined much more over the past ten years?

Other data of this survey also reveal that the number of highly educated people who seek help from "the Party and government departments" is lower compared with less educated ones, and the people who seek help from their "unit" take the highest share $(22.5 \%)$ among all groups. Correspondingly, the percentage of such people who adopt the "letters and visits" is the lowest among all groups as well. The message implied thereon should not be ignored. Does it indicate that the 
necessity of other means will be weakened if the units really work in this sense as an organizational channel? The reality in China is that the more-educated people are more likely to enter into the system-namely the classical units to get a position, so the data can reflect that most of people who do not serve the units lack the approaches to solve problems through "organizational channel"; therefore, they have to make claims through public channels (courts, Party and government departments, media, appeals and even the Internet).

\section{Connotations}

Compared with the similar survey data of previous years (of 1987 and 1999), the above changes turned out to be more obvious. The survey in 1987 showed that the units took a "dominant" position among all channels of expression. It functioned as a major channel of solving problems, and $72 \%$ of appeals were put forward through units. Twelve years later, the same survey conducted in 1999 showed that the percentage of individual respondents who dealt with problems through their units still ranked the first despite the drop. The percentage of channels including work units and "Party and government departments (including the groups of workers, youth and women)" was at the top of people's options. The comparison between the people with and without units may reveal a more meaningful hint, "The people who work in Party and government units have a problem-solving ability 8.5 times greater than those without units (Tang 2004).

Apparently the efficiency of units in solving problems declined dramatically over the past decades. Correspondingly between individuals and public systems those people who could benefit from the functions of units in terms of connection, accountability, coordination, representative and protection were also on the decline sharply. This implies a major transformation in our social organizational structure, which is shifting from the unit-based society to the public society.

This inevitably gives rise to the governance crisis as the units stood in the center of the governance structure and functioned as a responsible organization which enabled to realize social governance. The units as the intermediary of "government agencies" have two key roles: one is to function as a bridge-which is responsible for connecting individuals and larger public systems so that the information of social individuals may be delivered to higher authorities via the "organizational channels", influence the revision of policies through organizational game theory indirectly and effectively enhance the benefits of members of an organization; the other is the role to balance interests-which is responsible for error correction, coordination and settlement of interest conflicts. These two mechanisms of action are very significant to the grassroots, and provide institutionally recognized, convenient and available institutional channels for social members so as to indirectly get the response from the public systems. For social members, it is an important benefit to own and apply this channel. If the matter they appealed can enter into the regular handling procedures smoothly, they will make a big difference in their ability of improving their living. This may explain why members of a unit ask the leader to solve problems and generally require the unit to report "in the 
name of an organization" their own issues, or seek the "special approval" to solve problems through bypassing the barriers. Can't they report it by themselves? Yes, they can, but it has a different weight. That is because the higher authorities in the Chinese system only accept the reports submitted in the name of an organization; that is, the appeals that individuals deliver via its "organizational agencies" can be cherished and then enter into the procedures of handling. Apparently the rights to these institutional channels are endowed to (units) organizations, instead of individuals.

Hence the decline of unit-based society represents the disintegration of the "connection mechanism" and "mechanism of balanced interests" that originally covered most people and remained active at the grassroots society. When confronted with problems, more and more people cannot find the responsible organizations and as a result they hardly solve their own problems through the organizational channels. However the accountability mechanism applicable to the new public society is not established so that it cannot coordinate the conflicts through the alternative social equilibrium mechanism, which consequently directs the objects of social discontent towards the accountability of government. It can be said that the disintegration of grassroots organizational functions to "maintain justice" is just the crisis of social governance.

\section{Superior Position of Organizational Channels}

In comparison with individuals, the appeals launched by units with the "organizational identity" are not only submitted through more channels but also boast a higher efficiency (Fig. 1).

The average adoption frequency of the above channels suggest that the most commonly used channels by social organizations are "calling or writing letters to governmental officials", followed by the channel of "attending symposiums of governmental organizations" and submission of reports to the governments at a higher level, etc. However, such channels are barely available for individuals or cannot be used at all. For individuals, they are likely to call or write letters to their unit leaders, but such channels are less liable for governmental officials of public organizations because they are inaccessible to individuals and it is difficult to obtain their relevant information, such as their telephone number, address, etc. Individuals are not allowed to attend any symposium of governmental organizations as they are hardly invited. Individual reports also lack authority if they are not delivered in the name of organization (Table 5).

Compared with individuals, the danwei have a different identity and keep business relations with government departments. Hence, the groups supported by the government are more apt to solve problems through governmental procedures. To put it specifically the social organizations being supported by government departments during the incorporation process have a higher tendency of $43 \%$ than the units not being supported to apply the "governmental channels to propose 


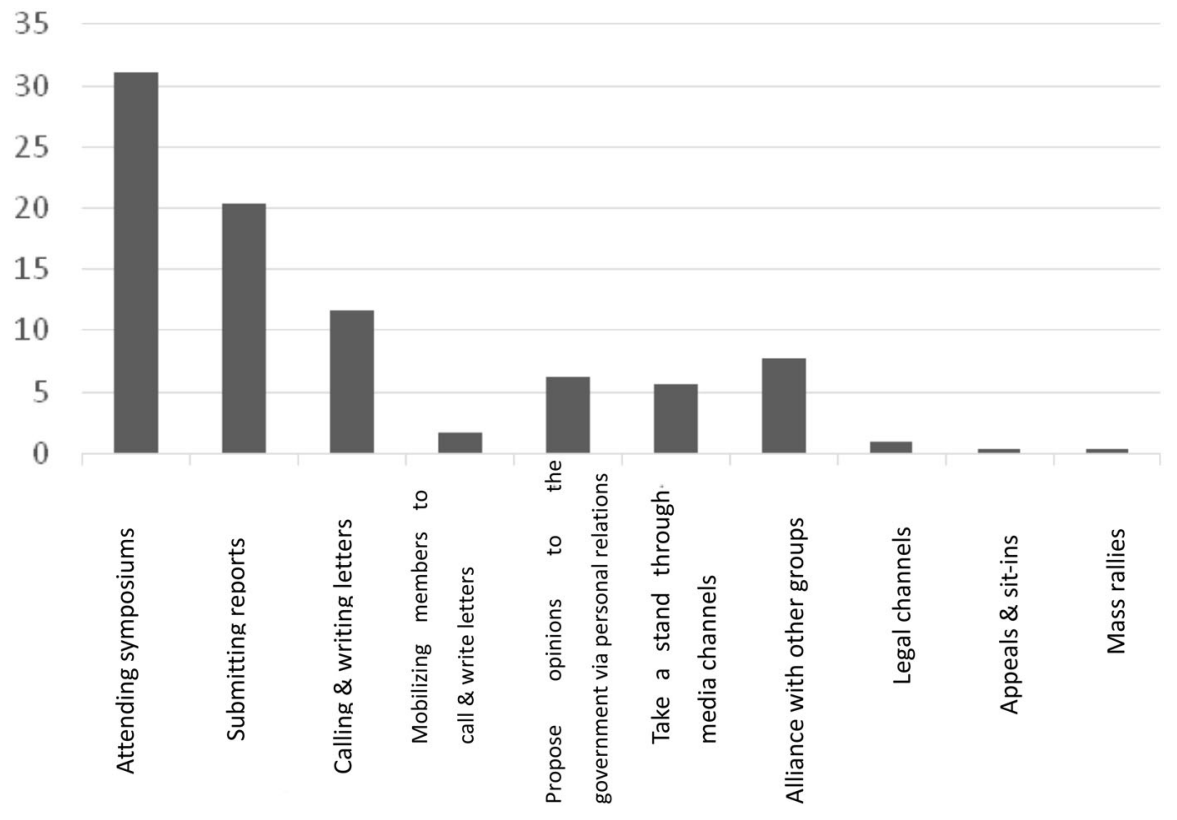

Fig. 1 Mode selection of appeals of social organizations. Valid organization samples: 1776. According to the Center for Civil Society Studies, Peking University: Survey Data of Social Organizations in Two Provinces, CSRC2010, statistics made by Jin Weiling

suggestions"; the tendency of units with administrative ranks to do so is $82 \%$ higher than that of the units without administrative ranks; the tendency of the units in contact with governmental officials to do so is $82 \%$ higher than those without such relations (Jin 2015) (Table 6).

The government shares the systems of financial allocation, personnel promotions and organizational positions similar to the legal department, so China implements the procedures different from those of the foreign countries which generally separate "legal channels" and "governmental channels". In China, the social organizations which draw support from the government are more likely to solve problems via legal channels, and the likelihood is 3.9 times higher than that of such units as receive no support from the government; the social organizations which remain in contact with governmental officials at the local or central level are more likely to adopt the legal channels, and the likelihood is 1.7-8 times higher than that of the groups that have no contact with such governmental officials (Table 7).

The dominant position of "organizational identity" endows the members of units with greater problem-solving abilities. Hence it casts light on the problem why a high percentage of communities give an affirmative answer to the question "if they should be subordinate to competent authorities". Similarly, a high percentage of communities give an affirmative answer to the question "if the subordination to communities is beneficial to themselves". Among the concerns of communities, the remarkably high proportion is reflected in two aspects: "increase in government 


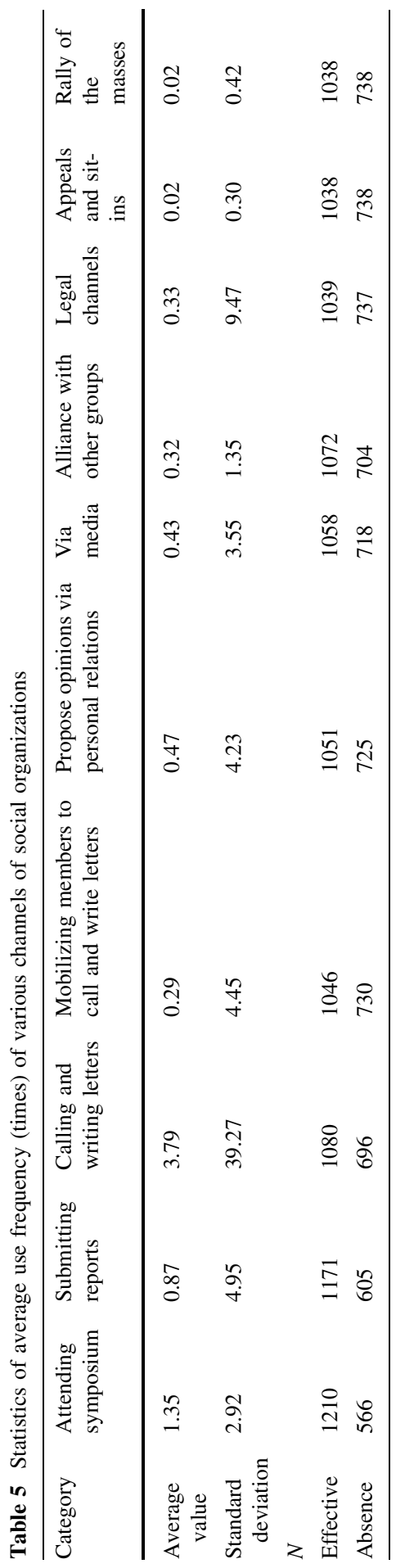


Table 6 Whether social organizations propose suggestions via governmental channels

\begin{tabular}{lllrlll}
\hline Zhengfu & Odds ratio & SE & \multicolumn{1}{l}{$z$} & $P>|z|$ & \multicolumn{2}{l}{ [95\% Conf. interval] } \\
\hline a5a & 1.429109 & 0.1966492 & 2.59 & 0.009 & 1.091284 & 1.871513 \\
a5b & 0.9760977 & 0.2176573 & -0.11 & 0.914 & 0.6305017 & 1.511125 \\
a5c & 1.097135 & 0.3438073 & 0.30 & 0.767 & 0.5936365 & 2.027681 \\
a5d & 0.6332602 & 0.5609326 & -0.52 & 0.606 & 0.1115836 & 3.593883 \\
a8 & 0.7950299 & 0.1674389 & -1.09 & 0.276 & 0.526156 & 1.201303 \\
b22 & 2.071291 & 0.525424 & 2.87 & 0.004 & 1.259844 & 3.405377 \\
b25a & 1.81522 & 0.3025917 & 3.58 & 0.000 & 1.309292 & 2.516645 \\
zhongyang & 1.094159 & 0.1629502 & 0.60 & 0.546 & 0.8171713 & 1.465033 \\
difang & 1.821903 & 0.3120065 & 3.50 & 0.000 & 1.30243 & 2.548568 \\
nei & 1.178489 & 0.0823807 & 2.35 & 0.019 & 1.027598 & 1.351536 \\
wai & 0.8281379 & 0.0559511 & -2.79 & 0.005 & 0.7254264 & 0.9453921 \\
_cons & 0.178594 & 0.0506343 & -6.08 & 0.000 & 0.1024559 & 0.3113125 \\
\hline
\end{tabular}

Logistic regression: number of obs $=964$

$\operatorname{LR} \operatorname{chi}^{2}(11)=76.02$

Prob $>$ chi $^{2}=0.0000$

Log likelihood $=-619.08571$ : pseudo $\mathrm{R} 2=0.0578$

Table 7 Whether community units solve problems via legal channels

\begin{tabular}{lllrllc}
\hline co & Odds ratio & SE & \multicolumn{1}{l}{$z$} & $P>|z|$ & \multicolumn{2}{l}{ [95\% Conf. interval] } \\
\hline a5 & 0.9761176 & 0.624102 & -0.04 & 0.970 & 0.278784 & 3.417719 \\
a8 & 1.163063 & 0.9387388 & 0.19 & 0.852 & 0.2390979 & 5.657577 \\
b22 & 1.20221 & 1.284788 & 0.17 & 0.863 & 0.1480169 & 9.764489 \\
b25a & 3.904532 & 2.379271 & 2.24 & 0.025 & 1.182714 & 12.89016 \\
zhongyang & 8.053762 & 6.475466 & 2.59 & 0.009 & 1.66574 & 38.9395 \\
difang & 1.731323 & 1.894346 & 0.50 & 0.616 & 0.2027808 & 14.78187 \\
nei & 0.6592457 & 0.2149385 & -1.28 & 0.201 & 0.3479558 & 1.249023 \\
wai & 0.6689394 & 0.201964 & -1.33 & 0.183 & 0.3701645 & 1.208868 \\
_cons & 0.0009682 & 0.201964 & -4.54 & 0.000 & 0.0000482 & 0.019434 \\
\hline
\end{tabular}

Logistic regression: number of obs $=1046$

$\operatorname{LR} \operatorname{chi}^{2}(8)=19.54$

Prob $>\mathrm{chi}^{2}=0.0122$

Log likelihood $=-55.773702$ : pseudo R2 $=0.1491$

allocations" and "expansion of recognition"; however, the lower percentage is seen in such items as "enhancement in professional ability", "elimination of regulatory constraints", "improvement in public policy" and "independence in personnel and property ownership" that are generally conducive to boosting the institutional autonomy of communities (Fig. 2). This reveals the expected relations between 


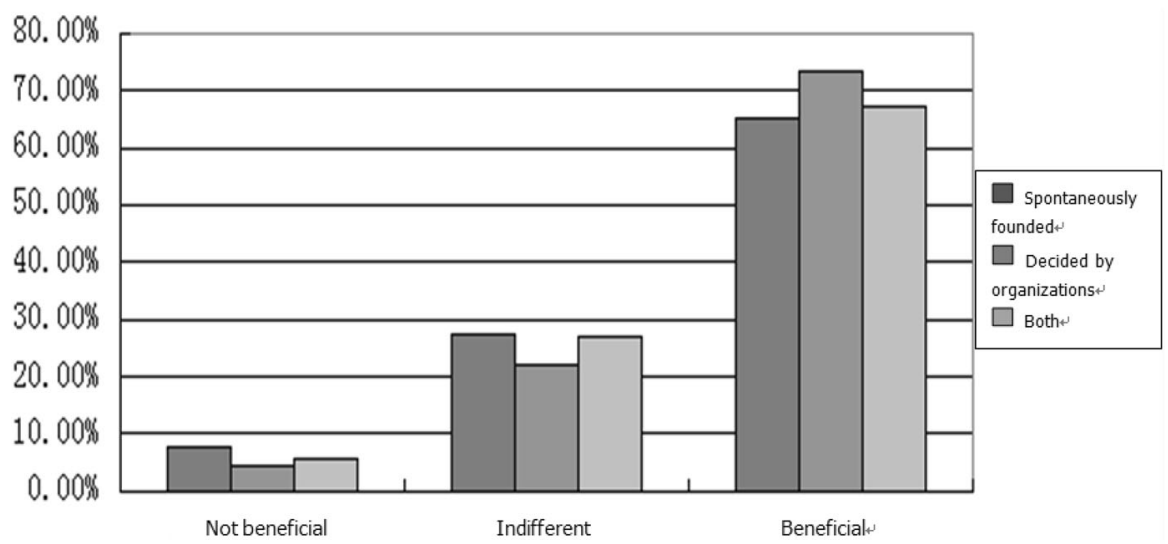

Fig. 2 Whether the subordination to competent authorities is beneficial to the activities of community activities

communities and government organizations: they are keener to approach such relations, instead of staying away (Zhang et al. 2014).

\section{Evidence of Cases}

The function of units in terms of connection, accountability, coordination and representing can either enhance or weaken the "national integration ability", which, therefore, brings about a large difference in the effect of social governance. The case study of a village in Guangdong can help us make sense of it.

Xiawei Village is situated in Zengcheng, east of Guangzhou. An upsurge of development and construction took place in the 1990s. On the strength of the favorable geographical and commercial conditions, a few storefront hotels and trade city projects were initiated successively. Naturally huge benefits were hidden behind the domination of these collective properties. Hence, Xiawei Village was confronted with disputes like other places during the process of getting rich: villagers harbored continuous doubts about all the links in the process such as land exploration, property lease, project contracting and account of gains. As the intense opposition lasted for over two decades, this village was seen as a unit with serious and longstanding problems in social governance. The village also gained a dubious fame for its tense relations between cadres and the masses. The first direct election of villagelevel cadres in 1999 did not turn out to be an opportunity to solve problems, but the government had to assign 400 policemen to "uphold the order" due to the extremely fierce situation in the election. In order to solve the problem of appeals in 2000, the Party Secretary of Zengcheng worked at a particular place of the village for three days and was besieged by the indignant villagers. During over 10 years thereafter, villagers appealed to the municipality, province and Beijing continuously... 
However, the years of conflicts were silenced in 2014. Correspondingly, Xiawei Village was changed from the renowned "village of problems" into the "civilized governance model village". What had happened then?

Most of the villagers were surnamed Guo and should be the generations of the same ancestors. Unfortunately, the same clan could not curb the internal dissension. The clique struggle was unfolded between two "cousinhood cliques" surnamed Guo. These two "cousinhood cliques" had their own core figures who acted as village cadres in turns, but one clique disagreed with the appointment of the other clique. The accountability organization did not exist then, so the appointment of each leading body was absolutely a new round of cadre-masses tension. If they both had someone elected into the leading body, the result was that they did not coordinate with each other so that it was hard to make any decision, and even harder to execute. For years, Xiawei Village had been swung around these two classes.

The clique struggles always share the clear but similar cause: One cousinhood clique prevented the other clique from holding power and gave many opportunities to their own cousinhood relatives, with a view to preventing them from suffering losses. In this view, the one clique fighting against corruption toppled the other party and elected the appointment of their own cousinhood figures. A few years later, they were ousted from office due to the complaints of the other party again. The protest was repeated again and again and upgraded continuously despite slight differences in contents. The dispute could not be solved locally, so the grouped villagers appealed to the governments at all levels increasingly. Although people understood that the sharp opposition in the village was no good for anyone, the properties were left unused. Whoever wanted to run would be obstructed. Clients had to give up business as they were unable to settle the disputes. The collective properties could not avail of themselves... However, the trouble was that people could not make any change. Due to the deep resentment between cliques, people would fight against each other whenever they met, which stopped everything. For over 20 years, the issue about how to "keep steady" in Xiawei Village had become a deadlock for grassroots governance.

In early 2014, Xiawei Village in the governance predicament established its "Villagers Meeting Hall", a 69-representative council in which 5-15 households on average out of 600 households in the village elected a representative according to the size of population. The meetings were held irregularly. The topics were selected from the villager platform on WeChat. Those with the most disputes and the great disagreement would be discussed first at the meeting. Where there is a discrepancy, the representatives will put forward a few plans and then vote through sharp debates. The plan that two-thirds of representatives vote for is the final resolution, on which all representatives must sign or affix their names for confirmation. The resolution will be announced on the spot. The proceedings will be publicized through WeChat. Any interested villagers outside the village may watch the proceedings via phone video. The Rules of Procedures of the village clarify that the two committees and villagers must "execute" the resolution once it is adopted, and "nobody is allowed to change or make other decision without authorization". The meeting is convened by the two committees of the village. In addition to speakers and representatives, the council also includes supervisor, delegates and audits. The 
members of the committee of the Party branch represented by villagers and the director of cooperatives can attend the meeting according to the stipulation, "and (they) have the right of discussion, without the voting power over the discussed matters". 6

As a decision-making platform for village affairs, the topics that Xiawei Village Council decides involve the following: the village's economy planning and social development, amendment bylaws of proceedings, approval of economic projects, contracting schemes, use and allocation of large sums, collective credits and loans, measures of asset disposal, and lease of such properties as collective land and houses, the raising plan of construction funds for public welfare establishments such as power, water, road and pipelining, construction contracting plan, distribution of house sites, distribution of compensation fees...To sum up, any matter involving collective assets and major concerns of villagers should be discussed and determined at the Meeting House. All the discussed proposals are related to the business opportunities, property disposal and profit-making methods of the village.

At the beginning, villagers still quarreled with one another. Some of them grabbed microphones, threw articles to speakers, splashed liquids, rebuked other speakers, damaged conference facilities, and stopped other representatives from entering the meeting site...Against such acts, the Rules of Procedures adapted the system of "yellow card (caution) or a red card (send off)": a representative, who is given two yellow cards cumulatively or one red card for his/her misconduct, will be suspended from voting power and right of procedures once. As the rules are neutral, yellow card is binding on conducts, instead of cliques. Villagers adapted to the new rules quickly than we imagine. Additionally representatives gradually chose selfdiscipline under the pressure of posts by villagers outside the meeting. The two cliques no longer fought with each other. Although the dispute is still fierce, both sides may sit together for negotiations. In less than one year, Xiawei Village Council successfully convened 16 meetings at which the representatives negotiated 38 topics, voted and adopted 29 topics, and denied 1 topic, with 8 pending resolutions. 23 of 29 adopted resolutions have been implemented. The two committees find that no villager hinders the progress of procedures. Such a situation has never existed over the past twenty years.

The council system was recognized by most villagers soon, and the two committees also receive better evaluations. The projects discussed at the Xiawei Village Council are seen with the unprecedented "satisfaction". The cadres feel very happy for such a situation: the village of appeals had realized the "zero appeal", for which they need not worry about being "trapped" any longer; villagers feel happier: the village's policy-making is so open that they don't worry about "suffering losses" any longer. The agreed methods have revitalized the collective properties left unused due to quarrels for years, upon the eventual consensus of opinions at present. The village is seen with increasing incomes and more investments in terms of annuity disbursement, welfare for the elderly, environmental sanitation and security facilities.

${ }^{6}$ Rules of Procedures of Xiawei Village, 2014. 
How did such a problem-plagued village overcome its problems under the mode of social governance? Why did not a new round of cadre-masses tension reoccur? It is because the organizational relations have been changed, and the system has covered all the masses. New organization rules widely include villager representatives-from more than 600 families, which cannot be controlled and composed of any clique. Additionally the open videos of proceedings enable representatives and villagers to witness the whole process of decision-making. Everyone shall reason things out at the meeting if they wish to influence 69 representatives and more than 600 families behind them; otherwise, they will not be entitled to serve the representative next time. For all villagers, this new organization is not formal, but profoundly changes the relations between them and the village organization in terms of rights, obligations and responsibilities.

Despite the same people and matters, the changed organizational relations give rise to very different results. The council has changed the domination of public property from personal will to public will. The village is kept orderly and more stable. Apparently, the exclusive decision-making power of cadres has been reduced, but they win more respect and prestige among villagers. This has enhanced their leadership: The high cooperation of villagers makes the village governed easier. During this change, the formerly most worries-social unrest and damage to the leading authority did not happen (Zhang 2015a, b).

This organizational system at the grassroots level has changed the relations between social members and governance system from confrontation to cooperation. Does this mean that the "national integration ability" has been strengthened?

\section{Response to Empirical Questions}

Now we can answer the empirical questions we put forward in the above argumentation. Why is the grassroots social governance of China invalid? It is because the dual governance system established in the middle of the last century is disintegrating in large dimensions. In that system, the organizations which actually undertook the responsibility for grassroots governance were the enterprises and institutional units - " agencies of the government" all over the society, instead of the government itself. The role of "indirect governance" evolved thereof, namely the working mode in which the government did not deal with governance issues directly and only oriented towards units instead of individuals, led the government to the failure to develop a sense of responsibility for the parties concerned. This may explain why the government was used to buck-passing and why it lacked the "governance ability". In the dual governance system, the status of government for approval and instruction enabled the government to decentralize its specific governance responsibilities to the units, instead of itself. When the disorganization of unit governance occurred, the sharp decrease of the organizations which were really responsible for governance was the root cause of the failure of grassroots social governance.

Why did the unit governance disintegrate? This was caused by the changes in the social environment. The former unit governance system was a result of the way of 
resource allocation at that moment, based on the social conditions with limited population mobility and higher homogeneity of organizations. However, the current governance issue is different: it is no longer the governance over an acquaintance society with partial closure, but the governance of a mobile and heterogeneous public society. The present means of resource allocation are also changed greatly. Many resources have been distributed in the market, in lieu of being monopolized by administrative organizations. Social members are less dependent on single organizations, with more choices. This is also an unprecedented and new environment. The adaptability of old governance system is reduced in face of new changes. Its governance efficiency has decreased enormously in the new organizational relations and interpersonal relationship. For example, the method of depending on interpersonal relationship or prejudicing the future benefits is binding on villages or units, but it will be out of action for a different social environment, i.e. a large-scale business society consisting of strangers. It never means that persons holding responsible for their families can also do so to passers-by. On the contrary, the more they concern their relatives and friends, the more possibly they compete with passers-by for resources, thus resulting in injustice. Apparently, the promotion of rules for relatives and friends is incapable of solving the governance issues of public society. It is a serious challenge for present governors about how to govern a social formation different from that in the past.

Why are some social differences non-political while others are transformed into political protest? As the shrinkage of unit functions is varying in place and organizational level, a few key mechanisms are also suffering different degrees of disintegration. The aspects of serious disintegration resulted in the disappearance of institutional channels and the progress stagnancy of public product-"social justice". Consequently, the conflicts arising from social differences could be hardly coordinated by virtue of this mechanism, which made the social sentiment accumulated and aggravated, and transformed to politicization. Hence, that's because the responsible organization could no longer arouse the injustice feelings rather than that the inequality of income resulted in the general governance difficulty. Such situation was unable to provide the organizational means of error correction, but to uphold the justice by settling the interest conflicts. If two groups are confronted with survival threats at the same time, some people have the responsible organization to act on behalf of their interests, while the others don't have. As the institutional channels for the latter to enhance their interests are blocked, the opportunity of addressing the unfair situation decreases naturally.

A review of different governance systems reveals that the maintenance mechanism of "social justice" really governs the society and can effectively establish the obedience order of the society. This mechanism supplements the role that is irreplaceable by the macro system. The multiple forms of organization and types of practice are available. The social governance is dependent on the active running of these mechanisms, but the specific form of organization for realization is subject to history and route. For example, the roles of connection, coordination, accountability, representative and protection as mentioned above exist in the gentry's organizations and units to a certain degree. Therefore, their actual role at 
the grassroots society, instead of the organizational forms, provides the most important public product for the society: upholding the justice.

\section{Exploration in Theoretical Issues}

Reviewing the functions of the above units in the whole social system, we may find a special organizational structure of the society: units, as the intermediary, organize social members into the national public system. For the grassroots, the units serve as the core of such organizational system. The decline of the unit-based society implies a change of social organizational structure: a great number of social individuals lose the structural identity of organization channels to connect with the national system. For example, many people from enterprises and institutions go into business and earn more money. Their economic capabilities are enhanced, but they still feel "as if they have lost something". Their status is degraded. This means a change of relations with public organizations, instead of ranking: they lose the identity of conveniently making use of the organizational channels. On the contrary, the existence of responsible organizations around them means that they have a favorable social position in the structure. This predicts a relation: the change in the social organizational structure may change the people's ability to make a living, and thus influence the reproduction of the political identity.

The change in social organizational structure may either enhance or weaken people's ability of survival. It enhances or weakens the individual survivability by three means: membership: whether an individual is admitted by an organization as its member; organization includes: whether individuals have the organizational channels to help them realize equities; structural access: whether individuals may be accessible to the public system to influence the policy and survive by relying on it. These three standards don't involve incomes or status difference, but the differences on the opportunity of social members to perform their rights are obvious: The people under the responsible organizations can realize their equities smoothly, while the others may hardly do so.

Compared with those social members with little or no access to organizational channels, those with organizational channels make a great progress in their ability of benefiting: they have more weights to influence and even change the execution of relevant policies. They have organizational channels dependable and help themselves to rectify errors. They have the institutional accountability organ which coordinates their relationship with other individuals or groups. They need not to take actions by themselves because the responsible organizations will address the issues and take actions on behalf of their interests. If people of this category can be given more opportunities to realize equities under the assurance offered by the political system, they will produce political identification of the system or sap their political identification of the system in the other way round. Hence, the structural relation between individuals and organizations may measure the people's political identity as it is related to the opportunity of realizing equities.

From another perspective, people who are able to establish such organizational relations and approaches have a strong ability of social integration and the 
superiority in obtaining people's political identification because the organizational structure can meet the needs for "channels of opportunity" of social members.

Acknowledgments I would like to thank three graduate students, Dong Yanfeng, Xin Guang and Jin Weiling, for their research assistance and contribution to this paper, and they respectively produce the statistical graphs about the survey data of GCSS2006 and CSRC2010.

\section{References}

Jin, Weiling. 2015. The statistics of problems solved by social organizations via governmental channels. Manuscript submitted for publication.

Li, Peilin, Chen, Guangjin and Xie, Shouguang. 2011. An interpretation of works of sociology of chinese academy of social sciences, 2011 blue book of China society: The analysis and forecast of China's social development. Online at Social Sciences Academic Press (China). http://www.21bcr.com/a/ shiye/guancha/2011/0222/2347.html.

Li, Wenyan and Sun, Guohui. 2009. An analysis on causes and countermeasures of enlarged income margin. Inner Mongolia: Northern Economy 22. Online at National People's Congress Economic Forum; (http://bbs.pinggu.org/thread-713896-1-1.html).

Lin, Chongyong. 2014. Major performance, cause and countermeasure for grassroots party cadres competing for benefits with the masses. Online at the Website of Nanning Discipline Inspection and Supervision Bureau: Theoretical Study. (http://www.nnlz.gov.cn/gzzc/llyj/201409/t20140923_ 187759.html).

Mao, Yushi. 2013. Where does the anxiety of the Chinese come from. Beijing: Qunyan Press.

Shue, V. 1988. The reach of the state: Sketches of the Chinese body politics. Stanford: Stanford University Press.

Sun, Liping. 2011. The scattered rage under the background of structural solidification. Beijing: Thinkers' Letters, Nov. Online at http://sun-liping.blog.sohu.com/205863778.html.

Tang, Wenfang. 2004. Publicity of personal opinions: A survey on residents of six cities in China, vol. 1, 48-72. Beijing: The Annual Sociology of Peking University.

Tong, Fei Xiao. 1953. China's Gentry. Chicago: University of Chicago Press.

Walder, A.G. 1996. Communist neo-traditionalism. Hong Kong: Oxford University Press (Hong Kong).

Wu, Xiaolin. 2012. Social stratum solidification in China: Importance shall be attached as much to the readjustment of the social structure as to the economic structure. Online at http://www.people.cn; (http://society.people.com.cn/GB/8217/17114262.html).

Yao, Jianjun. 2005. Ideological struggle under the situation of economic globalization and China 's countermeasures. (Master Dissertation, Jilin University, 2000). Online at http://www.docin.com/p337411740.html\&s=F9CFB08589C5073A7C90AF532F99CE5B.

Zhang, Jing, Wu, Suran and Jiao, Changquan. 2014. Objective, concern and responsibility-Survey report of social organizations. In Zhejiang: The review of new political economy. eds. Wang Dingding, Hangzhou: Zhejiang University Press. Issue in October 2014.

Zhang, Jing. 2012. Heterogeneity cohesion, published at the structural sources of social conflicts. Beijing: Social Science Academic Press.

Zhang, Jing. 2014. the Organized Foundation of Administrative Subcontract. Beijing: Chinese Journal of Sociology (6).

Zhang, Jing. 2015a. Transition of channels: Relevance between individuals and public organization. Jiangsu: Journal of Xuehai 1.

Zhang, Jing. 2015b. Why was the appealing village changed? Online at http://www.ftchinese.com; (http:// www.ftchinese.com/story/001060734?full=y).

Zhang, Yueran, Gao Bai. 2014. Institutional Analysis and Fiscal Sociology. Shanghai: Chinese Journal of Sociology 1. Online at http://www.doc88.com/p-8465595909230.html.

Zhongli, Zhang. 1991. Chinese gentry: Studies of their roles in the 19th-century chinese society. Shanghai: Shanghai Academy of Social Sciences Press. 
Dr. Jing Zhang Professor at Department of Sociology, is a researcher in the Center for Civil Society Studies at Peking University. Her research fields cover Political Sociology, Sociology of Law, and modern transition of Chinese society. She published books including The Unit of Organized Interests (2001), Problems of Rural Governance in China (2000, 2006), Corporatism (2001, 2005, 2015), The Public Rule in Rural China (2006), The State and Society (editor, 1999), Citizen Status Identity: Idea, Attitude, Certification (editor, 2006), Civic Justice in Transitional China (editor, 2008), Structural Source of Social Conflict" (2012). 